\title{
Decision Support System for Selection of Quality Doves with Web-Based Analytical Hierarchy Process (AHP) Methods
}

\section{Sistem Pendukung Keputusan Pemilihan Burung Merpati Berkualitas dengan Metode Analytical Hierarchy Process (AHP) Berbasis Web}

\author{
Ardhian Agil Ramadhan ${ }^{1 *}$, Suprianto ${ }^{2)}$, Surmarno $^{3)}$, Rohman Dijaya ${ }^{4)}$ \\ \{ardhianagilr@gmail.com ${ }^{1)}$, suprianto@umsida.ac.id ${ }^{2)}$, sumarno@umsida.ac.id ${ }^{3)}$,rohmandj@umsida.ac.id ${ }^{4)}$ \} \\ Program Studi Teknik Informatika, Fakultas Sains dan teknologi, Universitas Muhammadiyah Sidoarjo
}

\begin{abstract}
The purpose of making this system is to make it easier for breeders and pigeon lovers to determine high quality pigeons. The method used is the analytical hierarchy process (AHP), this method is used to support completing the program, using the analytical hierarchy process method, using the analytical hierarchy process method. this is because it can make it easier to make decisions. The result of this system is a web-based system that supports windows and linux operating systems, the purpose of making this system is to facilitate the decision making of high pigeons in determining quality pigeons that are integrated with database storage. The benefit of using this system is to facilitate the decision-making process for quality pigeons.
\end{abstract}

Keyword - Decision Support System Analytical Hierarchy Process method

Abstrak. Tujuan dari pembuatan dari sistem ini adalah untuk mempermudah para peternak dan pecinta burung merpati untuk menentukan merpati tinggian yang berkualitas.Metode yang digunakan yaitu analytical hierarchy process(AHP), Metode ini digunakan untuk mendukung dalam menyelesaikan program, menggunakan metode analytical hierarchy process, menggunakan metode ini dikarenakan dapat mempermudah dalam pengambilan keputusan. Hasil dari pembuatan sistem ini yaitu berupa sistem berbasis web yang mendukung sistem operasi windows dan linux, tujuan dari dari pembuatan sistem ini yaitu untuk mempermudah pengambilan keputuasn burung merpati tinggian dalam menentukan merpati yang berkualitas yang terintegrasi dengan penyimpanan database. Manfaat menggunakan sistem ini ialah untuk mempermudah proses pengambilan keputusan burung merpati berkualitas.

Kata Kunci - Sistem Pendukung Keputusan metode Analytical Hierarchy Process

\section{PENDAHULUAN}

Merpati merupakan salah satu unggas yang cukup dekat dengan manusia, burung merpati juga kerap kali di sebut dengan sebutan burung dara. Burung Merpati adalah burung yang memiliki ketangkasan dan kecepatan yang tinggi, Oleh Karena itu burung merpati cukup diminati sebagian orang.

Kecepatan dan ketangkasan burung merpati ini sering kali dimanfaatkan oleh para penggermarnya untuk mengikuti ajang perlombaan. Salah satunya ialah lomba Merpati tinggian. Pada merpati tinggian terdapat tiang yang terdapat tali yang berbentuk persegi diatasnya yang mana merpati datang sebisa mungkin harus melalui tengah dari persegi tersebut atau disebut kolong. Merpati kolong ada dua jenis pertama kolong bebas, kedua kolong meja. Pada merpati kolong meja disediakan meja didepan pemegang sang betina tempat burung mendarat nantinya. Sedangkan kolong bebas tidak terdapat meja, melainkan langsung dasar tanah. Peraturan sederhananya burung yang terlebih dahulu sampai menyentuh dasar atau tanah (kolong bebas) atau meja (kolong meja) dan berhasil melewati tali kolong diatas dialah yang menang. Jarak lepasan merpati kolong berkisar antara 1-2 km, lepasan dan tiang atau kolongnya biasanya tidak saling terlihat.[1]

Tentu tidak semua burung merpati dapat digunakan sebagai ajang lomba tinggian burung merpati. Merpati yang bisa di gunakan sebagai ajang lomba memiliki ciri-ciri atau parameter khusus agar dapat mementukan burung merpati tinggian berkualitas, pada umumnya merpati tinggian yang berkualitas di tentukan dari induk burung merpati, Postur tubuh, dan kualitas sayap.Karena melihat banyaknya penggemar burung merpati tinggian dan burung merpati yang dapat digunakan sebagai ajang lomba memiliki parameter khusus perlu adanya sebuah sistem agar dapat memudahkan pecinta burung merpati tinggian agar dapat menentukan kulalitas dari burung merpati tersebut 


\section{METODE}

\section{A. Sistem pendukung keputusan}

Sistem pendukung keputusan adalah bagian dari sistem informasi berbasis komputer yang digunakan untuk mendukung pengambilan suatu keputusan dalam organisasi. dapat juga diartikan sebagai sistem komputer yang dapat digunakan untuk mengelolah sebuah data menjadi informasi yang digunakan untuk mengambil keputusan dari masalah yang semi terstruktur yang spesifik.[2]

Menurut pendapat Moore and Chang, Sistem pendukung keuputusan adalah sistem yang memiliki kemampuan mendukung analisis data, dan pemodelan keputusan, berorientasi keputusan, orientasi perencanaan masa depan, dan juga dapat digunakan pada saat-saat tidak biasa.[3]

\section{B. Proses dalam sistem pendukung keputusan}

Tahap-tahap pengambilan keputusan harus dilalui dalam proses pengembilan keputusan ialah sebagai berikut :

1) Penelurusan linkung masalah

2) Perancangan penyelesaian masalah

3) Pemilhan tindakan

4) Pelaksanaan tindakan.[4]

\section{Analytical Hierarchy Process (AHP)}

Metode Analytical Hierarchy Process (AHP) merupakan suatu model pendukung keputuan yang dikembangkan oleh Thomas L.Saaty. model pendukung keputusan ini dapat menguraikan masalah dalam multi faktor atau multi kriteria yang kompleks menjadi suatu hirarki, Menurut Taylor (2014), AHP adalah sebuah metode untuk memeringkat alternatif keputusan dan memilih yang terbaik dengan beberapa kriteria. AHP mengembangkan satu nilai numerik untuk memeringkat setiap alternatif keputusan, berdasarkan pada sejauh mana tiap-tiap alternatif memenuhi kriteria pengambil keputusan.[5]

\section{Kelebihan AHP}

a) Struktur yang berhierarki sebagai konsekuensi dari kriteria yang dipilih sampai pada sub-sub kriteria yang paling dalam .

b) Memperhitungkan validalitas sampai batas toleransi inkonsentrasi sebagai kriteria dan alternatif yang dipilih oleh pengambil keputusan.

c) Saling ketergantungan (Inter Dependence), AHP bisa diterapkan pada elemen-elemen sistem yang tidak sama sama berhubungan dan tidak membutuhkan hubungan linier.

d) Memperhitungkan daya tahan atau ketahanan output analisis sensivitas pengambil keputusan .AHP mempunyai kemampuan untuk menyelesaikan sebuah masalah yang diteliti dari multi objek kriteria yang berdasar dari suatu perbandingan preferensi dari tiap elemen.

\section{E. Kekurangan AHP}

Metode AHP ini bergantung pada input utamanya. Input utama yang dimaksud ialah suatu pendapat seorang ahli sehingga dalam hal ini juga harus melibatkan subyektifitas seorang ahli, selain itu juga model menjadi tidak berarti jika seorang ahli tersebut memberikan penilaian yang tidak benar.[6]

\section{F. Perhitungan Metode AHP}

Metode AHP dikembangkan sebagai algortima pengambilan keputusan untuk permasalahan multikriteria. Permasalahan multikriteria dalam AHP disederhanakan dalam bentuk hierarki yang terdiri dari 3 komponen utama, yaitu tujuan dari pengambilan keputusan, kriteria penilaian dan alternatif pilihan.[7]

Adapun tahapan perhitungan AHP sebagai berikut:

1. Mendefinisikan suatu masalah dan solusinya. Setelah itu membuat struktur hierarki

2. Membuat tabel matrik berpasangan

3. Dilanjutkan dengan pairwise comparison (perbandingan berpasangan), tingkat kepentingan suatu kriteria dibandingkan dengan yang lain dapat dijabarkan.

4. Mengitung nilai eigen dan menguji kositensinya. Pengambilan data akan diulang apabila tidak konsisten.

5. Menghitung eigenvector dari matrik perbandingan berpasangan

6. Memeriksa konsistensi hierarki dengan rumus. 


\section{HASIL DAN PEMBAHASAN}

\section{A. Perancangan sistem}

Dalam membuat perancangan sistem ada beberapa tahapan yang perlu dilakukan. Tahapan yang dilakukan untuk merancang sistem tersebut adalah membuat Diagram Konteks, Data Flow Diagram (DFD), dan Flowchart.[8]

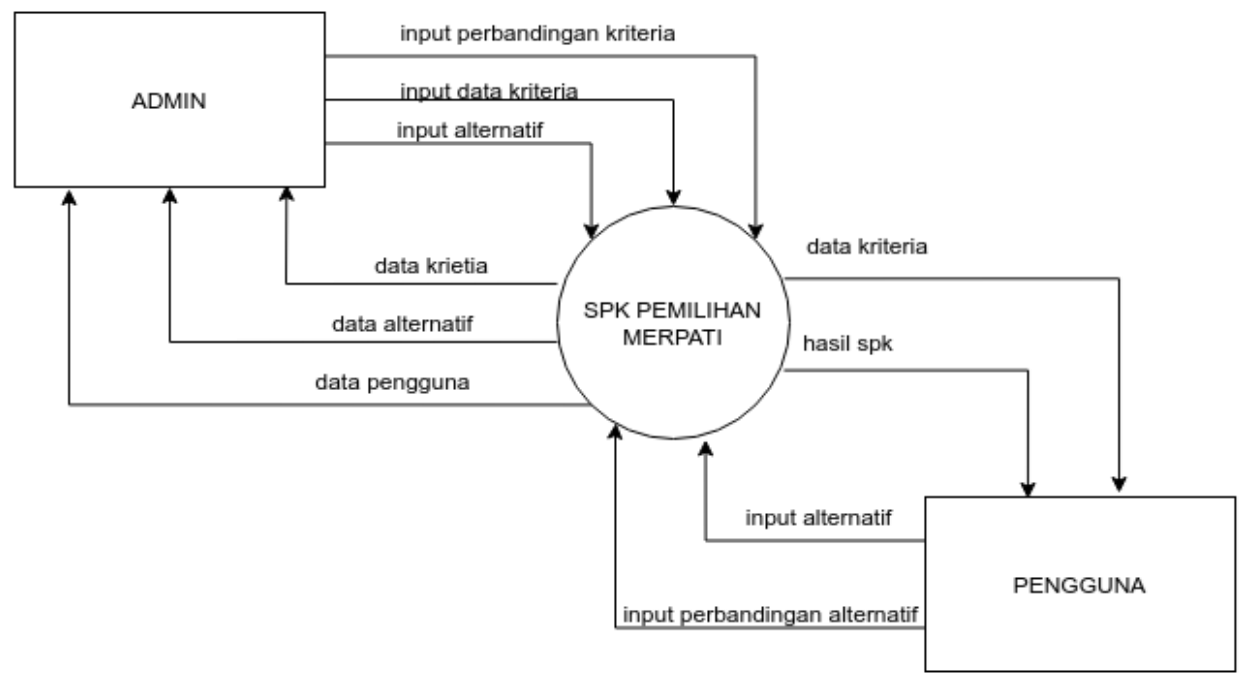

Gambar 1. Diagram Konteks

Dari diagram konteks diatas dapat dilihat bahwa ada beberapa entitas luar yang terhubung dengan sistem pendukung keputusan yang berfungsi sebagai bahan untuk menentukan burung merpati berkualitas di desa Jemirahan RT 02 RW 01, kecamatan Jabon, kabupaten Sidoarjo.

Admin yang memiliki tugas untuk mengelolah sistem dengan cara login terlebih dahulu agar bisa menginputkan alternatif dan nilai perbandingan yang diperlukan sistem pengambilan keputusan pemilihan burung merpati. Sedangkan pengguna melakukan input data, kemudian akan diproses sehingga akan menghasilkan luaran berupa laporan pemilihan burung merpati berkualitas[9].

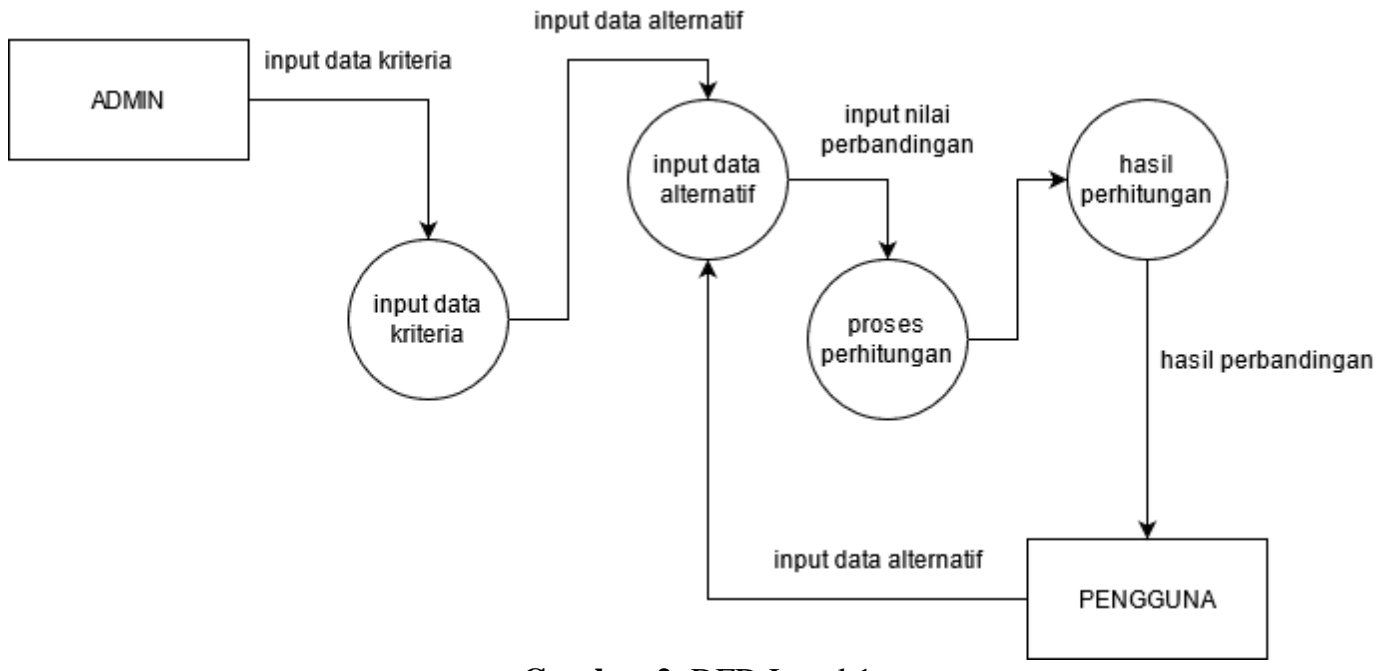

Gambar 2. DFD Level 1

Dapat dilihat pada DFD level 1 yaitu ada 4 proses antara lain:

1. Proses input kriteria. Proses ini berfunsi untuk mengisikan data kriteria yang di perlukan untuk pemenuhan syarat pemilihan burung merpati berkualitas dan akan di proses menggunakan metode Analytical Hierarchy Process. 
2. Proses input alternatif. Proses ini berfunsi untuk mengisikan data alternatif yang di perlukan untuk pemenuhan syarat pemilihan induk burung merpati Berkualitas dan akan di proses menggunakan metode Analytical Hierarchy Process.

3. Proses SPK. Proses ini mengambil dari data alternatif dan kriteria serta nilai perbandingan yang kemudian akan diproses untuk menghasilkan suatu sistem pengambilan keputusan dimana sistem ini berfungsi untuk menyeleksi data burung merpati yang berkualitas untuk digunakan untuk beternak di desa Jemirahan RT 02 RW 01, kecamatan Jabon, kabupaten Sidoarjo.

4. Proses laporan. Proses ini berfungsi untuk menampilkan laporan dari hasil penyeleksian di proses SPK burung merpati yang berkualitas. Laporan akan diberikan kepada admin atau pengguna yang mempunyai peternakan burung merpati.

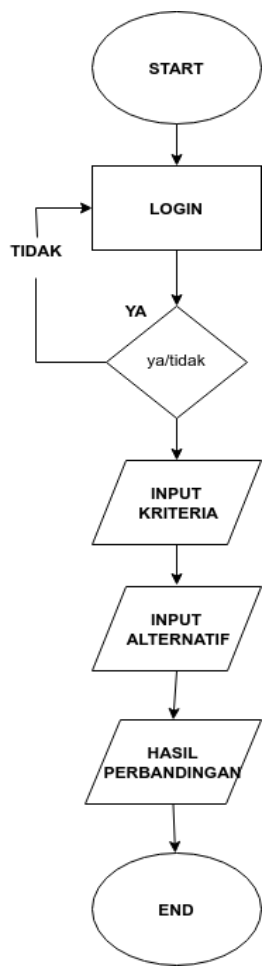

Gambar 4. Flowchart System

Dari gambar flowchart system diatas dapat dilihat bahwa sistem yang akan digunakan untuk aplikasi pada penelitian ini yaitu dimulai dari proses login apabila login gagal akan kembali ke proses login dan apabila login sukses akan menuju ke penginputan data alternatif dan nilai perbandingan, setelah itu disimpan dan kemudian akan diproses dan diseleksi menggunakan metode AHP. Setelah selesai perhitungan akan menjadi suatu laporan lalu data akan keluar alternatif yang terbaik dan selesai.

\section{B. Perhitungan mentode AHP}

Dari data burung merpati diatas variabel Postur tubuh, keturunan, dan bentuk sayap dapat dikategorikan menjadi tabel sebagai berikut:

Tabel 1. Kategori Data Burung Merpati

\begin{tabular}{ccccc}
\hline No & Burung Merpat & Postur Tubul & Keturunn & Bentuk Sayap \\
\hline 1 & Merpati 1 & C & B & B \\
2 & Merpati 2 & B & B & B \\
3 & Merpati 3 & D & D & B \\
4 & Merpati 4 & A & A & A \\
5 & Merpati 5 & B & B & B \\
\hline
\end{tabular}


Procedia of Engineering and Life Science Vol. 1. No. 2 Juni 2021

Seminar Nasional \& Call Paper Fakultas Sains dan Teknologi (SENASAINS 2nd)

Universitas Muhammadiyah Sidoarjo

Tabel 2. Variabel Postur Tubuh Perbandingan Berpasangan

\begin{tabular}{lccccc}
\hline & Merpati & Merpati & Merpati & Merpati & Merpati5 \\
\hline Merpati 1 & $1 / 1$ & $1 / 2$ & $2 / 1$ & $1 / 3$ & $1 / 2$ \\
Merpati 2 & $2 / 1$ & $1 / 1$ & $3 / 1$ & $1 / 2$ & $1 / 1$ \\
Merpati 3 & $1 / 2$ & $1 / 3$ & $1 / 1$ & $1 / 4$ & $1 / 3$ \\
Merpati 4 & $3 / 1$ & $2 / 1$ & $4 / 1$ & $1 / 1$ & $2 / 1$ \\
Merpati 5 & $2 / 1$ & $1 / 1$ & $3 / 1$ & $1 / 2$ & $1 / 1$ \\
\hline
\end{tabular}

Tahap 1: Kuadratkan Matrik Berpasangan

1. Kali kan antara kolom pertama dengan baris pertama.

2. Kali kan antara kolom pertama dengan baris kedua.

3. Kali kan antar kolom pertama dengan baris ketiga.

4. Untuk kolom seterusnya juga sama.

Tabel 3. Matrik Berpasangan

\begin{tabular}{lccccc}
\hline & Merpati 1 & Merpati 2 & Merpati 3 & $\begin{array}{c}\text { Merpati } \\
\mathbf{4}\end{array}$ & Merpati5 \\
\hline Merpati 1 & 1,0 & 0,5 & 2,0 & 0,33 & 0,5 \\
Merpati 2 & 2,0 & 1,0 & 3,0 & 0,5 & 1,0 \\
Merpati 3 & 0,5 & 0,33 & 1,0 & 0,25 & 0,33 \\
Merpati 4 & 3,0 & 2,0 & 4,0 & 1,0 & 2,0 \\
Merpati 5 & 2,0 & 1,0 & 3,0 & 5,0 & 1,0 \\
\hline
\end{tabular}

Berikut adalah hasil dari perkalian matrik berpasangan:

Tabel 4. Hasil Perkalian Matrik Berpsangan

\begin{tabular}{ccccc}
\hline 4,99 & 2,37 & 8,32 & 3,91 & 2,82 \\
\hline 9 & 4,99 & 15 & 7,41 & 4,99 \\
3,07 & 1,74 & 4,98 & 2,48 & 1,74 \\
16 & 8,82 & 26 & 13,99 & 8,82 \\
40,5 & 13,99 & 36 & 11,91 & 13,99 \\
\hline
\end{tabular}

Tahap 2: Menghitung Eigenvector pertama

1. Jumlahkan semua baris.

2. Jumlahkan jumlah dari semua baris-baris yang ada.

3. Normalisasi nilai jumlah dari masing-masing semua baris.

Tabel 5. Perhitungan Eigenvector Pertama

\begin{tabular}{ccccccc}
\hline 4,99 & 2,37 & 8,32 & 3,91 & 2,82 & & \\
\hline 9 & 4,99 & 15 & 7,41 & 4,99 & $=$ & 41,39 \\
3,07 & 1,74 & 4,98 & 2,48 & 1,74 & & 73,63 \\
16 & 8,82 & 26 & 13,99 & 8,82 & 116,39 \\
40,5 & 13,99 & 36 & 11,91 & 13,99 & & 267,83 \\
\hline
\end{tabular}


Procedia of Engineering and Life Science Vol. 1. No. 2 Juni 2021

Seminar Nasional \& Call Paper Fakultas Sains dan Teknologi (SENASAINS 2nd)

Universitas Muhammadiyah Sidoarjo

Jumlahkan setiap baris lalu tambahkan hasil dari setiap baris $(4,99+2,37+8.32+3,91+2,82=22,41)$.

Tahap 3: Normalisasi

Hasil dari angka normalisasi pertama yang sebesar 0.0836725 didapatkan dengan membagi angka 22,4 : 267,83

Jadi Eigenvector untuk variabel Usia adalah:

Tabel 6. Eigenvector Variabel Postur Tubuh

\begin{tabular}{ll}
\hline Merpati 1 & 0,0836725 \\
\hline Merpati 2 & 0,1545383 \\
Merpati 3 & 0,0523093 \\
Merpati 4 & 0,2749132 \\
Merpati 5 & 0,4345667 \\
\hline
\end{tabular}

Dari matrik ini dihitung eigenvector, untuk menetukan peringkat dari alternatif pilihan untuk masing - masing kriteria sebagai berikut:

Tabel 7. Eigenvector Variabel Keturunan

\begin{tabular}{ll}
\hline Merpati 1 & 0,1916095 \\
\hline Merpati 2 & 0,1916095 \\
Merpati 3 & 0,0690145 \\
Merpati 4 & 0,3561569 \\
Merpati 5 & 0,1916095 \\
\hline
\end{tabular}

Dari matrik ini dihitung eigenvector, untuk menetukan peringkat dari alternatif pilihan untuk masing - masing kriteria sebagai berikut:

Tabel 8. Eigenvector Variabel Bentuk Sayap

\begin{tabular}{ll}
\hline Merpati 1 & 0,1552795 \\
\hline Merpati 2 & 0,1552795 \\
Merpati 3 & 0,1552795 \\
Merpati 4 & 0,3616287 \\
Merpati 5 & 0,1725328 \\
\hline
\end{tabular}

Tahap 5: Perangkingan

Dengan menormalisasi semua informasi bersifat quantitative, akan bisa didapatkan peringkat untuk masingmasing alternatif pilihan. Dan dengan demikian bobot kriteria dan alternatif pilihan sudah terlengkapi.

Untuk mendapatkan hasil keputusan, masing-masing bobot untuk alternatif pilihan dikalikan dengan bobot dari kriteria dalam bentuk perkalian matrik sebagai berikut:

Tabel 9. Perkalian Matrik

\begin{tabular}{lllllll}
\cline { 1 - 3 } Merpati 1 & 0,0836725 & 0,1916095 & 0,1552795 & & 0,3196 \\
\hline Merpati 2 & 0,1545383 & 0,1916095 & $\mathbf{1} 0,1552795$ & & 0,5584 \\
Merpati 3 & 0,0523093 & 0,0690145 & & 0,1552795 & & 0,1120 \\
\hline Merpati 4 & 0,2749132 & 0,3561569 & & 0,3616287 & & \\
Merpati 5 & 0,4345667 & 0,1916095 & 0,1725328 & & \\
\hline
\end{tabular}


Procedia of Engineering and Life Science Vol. 1. No. 2 Juni 2021

Seminar Nasional \& Call Paper Fakultas Sains dan Teknologi (SENASAINS 2nd)

Universitas Muhammadiyah Sidoarjo

Sehingga perhitungan untuk keseluruhan nilai masing-masing alternatif pilihan adalah sebagai berikut:

Tabel 10. Hasil Perkalian Matrik

\begin{tabular}{ll}
\hline Merpati 1 & 0,1536562 \\
\hline Merpati 2 & 0,1753293 \\
Merpati 3 & 0,0741998 \\
Merpati 4 & 0,3272427 \\
Merpati 5 & 0,2669313 \\
\hline
\end{tabular}

Sehingga pilihan yang paling bagus untuk kasus pengambilan keputusan ini adalah Merpati 4.

\section{Pengujian sistem}

Setelah dilakukan pengimplementasian sistem, maka tahapan selanjutnya adalah pengujian sistem dari hasil perhitungan dari data yang ada dengan menggunakan metode Analytical Hierarchy Process (AHP) secara matematis dibandingkan dengan output yang dihasilkan oleh sistem apakah sesuai atau tidak.

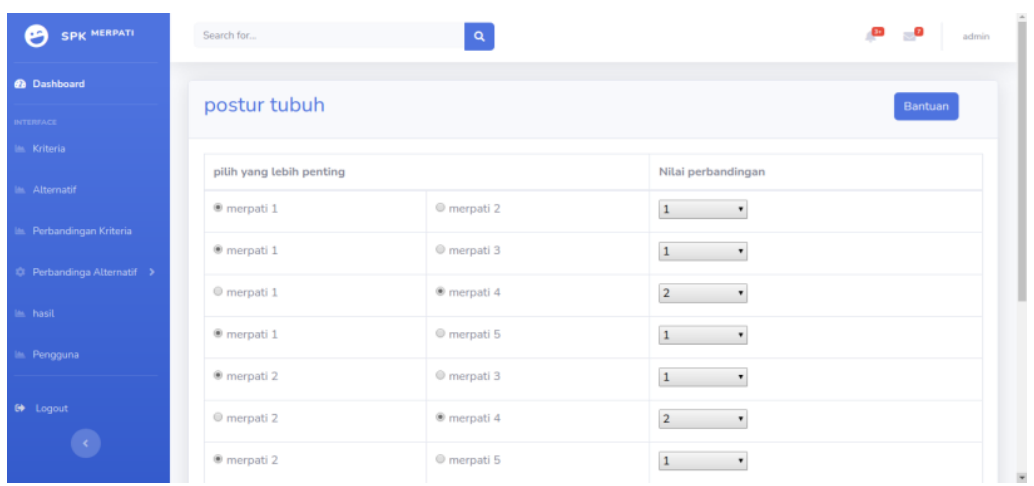

Gambar 7. Perbandingan Alternatif Postur tubuh

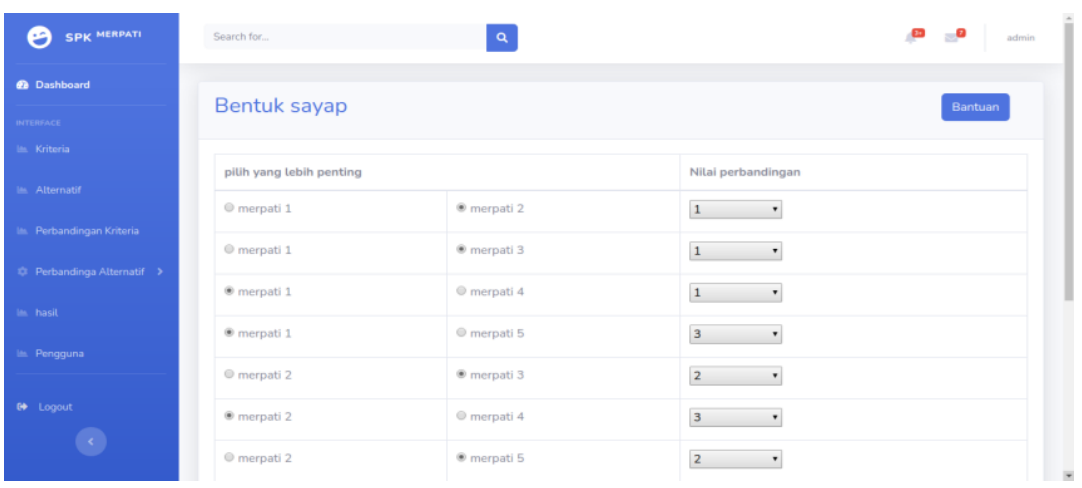

Gambar 8. Perbandingan Alternatif Bentuk Sayap

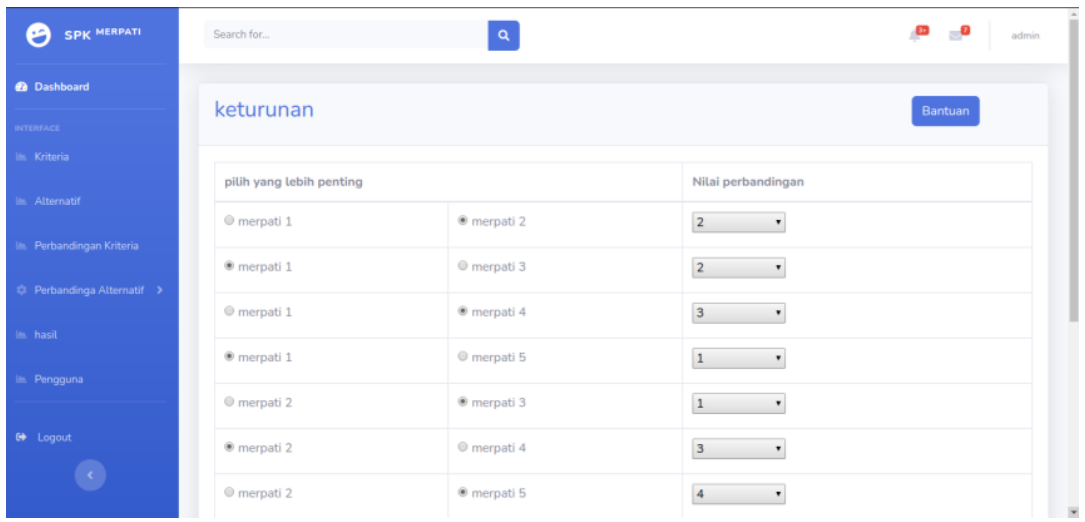

Gambar 9. Perbandingan Alternatif Keturunan 
Procedia of Engineering and Life Science Vol. 1. No. 2 Juni 2021

Seminar Nasional \& Call Paper Fakultas Sains dan Teknologi (SENASAINS 2nd)

Universitas Muhammadiyah Sidoarjo
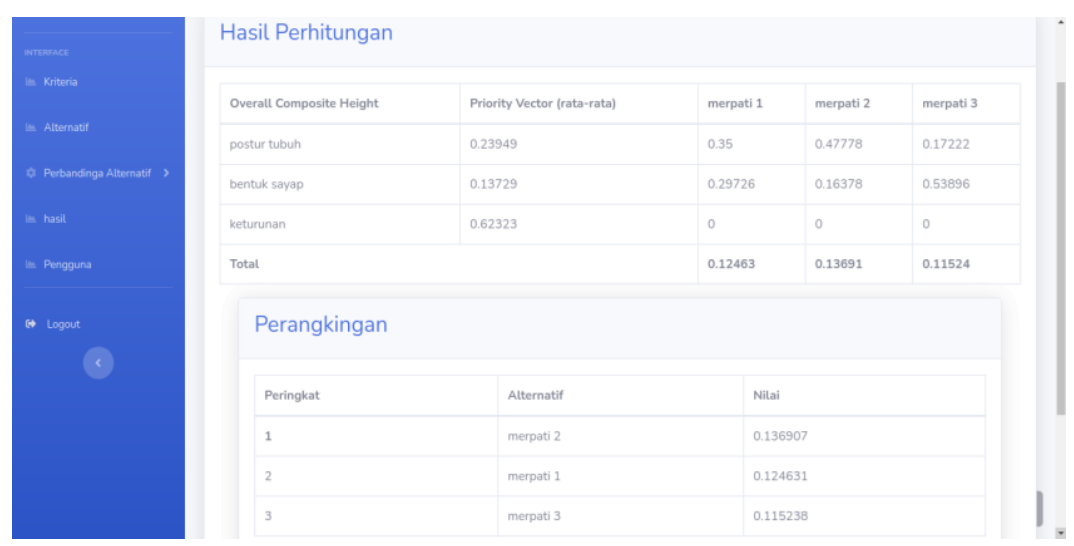

Gambar 10. Menu Hasil

\section{KESIMPULAN}

Berdasarkan dari hasil percobaan dan juga analisa yang telah dilakukan, maka didapat diatrik kesimpulan sebagai berikut: Aplikasi sistem pendukung keputusan pemilihan burung merpati berkualitas dengaSn metode analytical hierarchy process (AHP) berbasis web dapat digunakan sebagai sistem yang membantu peternak burung merpati untuk memilih merpati yang berkualitas. Sistem ini sudah diuji cobakan pada berbagai perangkat komputer yang memiliki spesifikasi setara. Hasil uji coba sistem sudah sesuai dengan hasil pemilihan burung merpati berkualitas yang dilakukan oleh peternak burung merpati yang bertempat di desa Jemirahan RT 02 RW 01, kecamatan Jabon, kabupaten Sidoarjo. Sistem ini memiliki keunggulan yaitu, admin atau pengguna tidak akan mengalami kesulitan guna untuk menentukan hasil pemilihan burung merpati berkualitas dan sistem ini memiliki tampilan yang bersifat user friendly.

\section{UCAPAN TERIMA KASIH}

Keberhasilan penelitian ini tidak lepas dari bimbingan, bantuan, dorongan semangat dari berbagai pihak. Oleh karena itu dengan segala kerendahan hati penulis ingin mengucapkan terima kasih kepada seluruh pihak yang berperan dalam penelitian ini.

\section{DAFTAR PUSTAKA}

[1] Habibi. (2019). Jenis permainan burung merpati yang populer di indonesia Dikutip Desember 22, 2019 dari Duniahobi.org: https://duniahobi.org/burung/merpati/jenis-permainan-burung-merpati/

[2] Aris Kurniawan. (2017). sistem pendukung keputusan berserta komponen, manfaat dan tujuan lengkap. Dikutip Desember 22, 2019 dari Gurupendidikan.co.id : www.gurupendidikan.co.id/sistem-pendukung-keputusan

[3] Moore and Chang. (2011). Pengertian Sistem Pendukung Keputusan. Penerbit Andi Offeset, jogjakarta, 2011.

[4] Yananto. (2019).proses dalam pengambilan keputusan. Dikutip Juni 19, 2019 dari yananto : http://43217120002.blog.mercubuana.ac.id/2019/06/19/sistem-pengambilan-keputusan/

[5] Taylor (2014). Pengertian Metode Ahp. Dikutip desember 22, 2019 dari raharja.ac.id https://raharja.ac.id/2020/03/31/analytical-hierarchy-process-ahp/

[6] Ulty (2019). kekurangan Metode Ahp. Dikutip desember 29, 2020 dari lancangkuning.com http://lancangkuning.com/post/14827/keuntungan-dan-kelamahan-metode-ahp.html

[7] Setiawan, Herdi. (2015). Metode Dan Cara Perhitungan AHP. Dikutip Juli 22, 2019 dari herdiset : https://herdiset.wordpress.com/2015/01/16/metode-ahp-dan-cara-perhitungan-ahp.html

[8] Kristanto, Andri. (2017). Perancangan Sistem Informasi Dan Aplikasinya. Penerbit Gava Media. Klaten. https://lancangkuning.com/post/14827/keuntungan-dan-kelemahan-metode-ahp.html

[9] Ahmad, anshori. (2020).proses alur perancangan data flow diagram. Dikutip maret 28, 2020 dari . https://www.ansoriweb.com/2020/03/pengertian-dfd.html

[10] Sarah R.Megumi. (2017). Burung merpati,lebih dari sekedar peliharaan. Dikutip desember 22, 2019 dari greeners.co: https://www.greeners.co/flora-fauna/burung-merpati-lebih-sekadar-peliharaan/ 